\title{
THE EFFECTS OF BALANCE TRAINING ON BALANCE ABILITY IN HANDBALL PLAYERS
}

\author{
Asimenia Gioftsidou*, Paraskevi Malliou, Polina Sofokleous, George Pafis, \\ Anastasia Beneka, and George Godolias \\ Department of Physical Education and Sports Science, Democritus University of Thrace, \\ Komotini, Greece
}

\begin{abstract}
The purpose of the present study was to investigate, the effectiveness of a balance training program in male professional handball players. Thirty professional handball players were randomly divided into experimental and control group. The experimental group $(\mathrm{N}=15)$, additional to the training program, followed an intervention balance program for 12 weeks. All subjects performed a static balance test (deviations from the horizontal plane). The results revealed that the 12 -week balance training program improved $(\mathrm{p}<0.01)$ all balance performance indicators in the experimental group. Thus, a balance training program can increase balance ability of handball players, and could used as a prevent tool for lower limbs muscular skeletal injuries.
\end{abstract}

Keywords: handball players, proprioception, balance training

\section{Introduction}

Handball is one of the most popular European team sports along with soccer, basketball and volleyball (Petersen et al., 2005). The sport medicine literature reports team sports participants, such as handball, soccer, hockey, or basketball players, reported an increased risk of traumatic events, especially to their lower extremity joints (Hawkins, and Fuller, 1999; Meeuwisse et al., 2003; Wedderkopp et al 1997; 1999). Injuries often occur in noncontact situations (Hawkins, and Fuller, 1999; Hertel et al., 2006) resulting in substantial and long-term functional impairments (Zech et al., 2009).

The jumping and pivoting activities contained in team sports have been described as injury risk factors by many authors proposing prevention strategies based on improving athletes balance ability (Caraffa et al., 1996; Hewett 2001; Junge 2002). Also, rehabilitation bibliography supports that balance exercise programs may improve proprioceptive function not only during rehabilitation but also during the competition period, protecting athletes from forthcoming injuries effectively (Caraffa et al., 1996; Hoffman \& Payne, 1995; Hewett et al., 1999; Wedderkopp et al., 1999; Hrysomallis, 2007; McHugh et al., 2007).

\footnotetext{
* Corresponding author. Department of Physical Education and Sports Sciences, Democritus University
} of Thrace, Campus 69100 Komotini, Greece, e-mail: agioftsi@phyed.duth.gr 


\section{A. Gioftsidou et al.}

Balance is generally defined as the ability to maintain the body's center of gravity within its base of support and can be categorized as either static or dynamic balance. Static balance is the ability to sustain the body in static equilibrium or within its base of support (Goldie et al., 1989; Olmsted et al., 2002). Dynamic balance is supported to be more challenging because it requires the ability to maintain equilibrium during a transition from a dynamic to a static state (Ross and Guskiewicz, 2004). Both static and dynamic balance require integration of visual, vestibular, and proprioceptive inputs to produce an efferent response to control the body within its base of support (Irrgang et al., 1994; Guskiewicz and Perrin, 1996).

In addition, Hanney (2000) states that proprioception is "the reception of stimuli produced within organism", whereas balance is "physical equilibrium" (Hanney, 2000). This means that proprioception is a neurologic process, while balance is the ability to remain in an upright position (Hanney, 2000). Balance exercises aimed at improving proprioception; train the brain to recognize the body's segment position every moment. Therefore, a balance exercise program will train and facilitate proprioception pathways under competitive circumstances effectively. Specifically, in order to prevent limb injuries, peripheral and central nervous system receptors (Hanney, 2000), mechanoreceptors within muscles, tendons, and ligaments have to be activated and guide the body segments to move properly. Thus balance exercises seem to help this activation occur faster and more effectively (Sammarco, 1995). In other words, the goal of balance exercises possibly reduce the time between neural stimuli and muscular response (Zachazewski et al., 1996) preventing forthcoming injuries.

Furthermore, many scientists (Bahr et al., 1997; Caraffa et al., 1996; Wedderkopp et al., 1999; Soderman et al., 2000; Malliou et al., 2004; Gioftsidou et al 2006) support that balance exercises are essential to athletic performance and should be incorporated into an athlete's daily training. Recently published studies have shown that it is possible to prevent lower extremity injuries in handball (Petersen et al., 2002; Wedderkopp et al., 2003; Olsen et al., 2005). However, there were no studies measuring balance parameters and their possible improvements after an application of a specific balance exercise program in professional male handball players.

The purpose of the present study was to investigate the effectiveness of a balance training program in handball players, aiming to improve proprioceptive ability.

\section{Method}

\section{Participants}

Following written, informed consent from each player and clearance from the University Human Subjects Committee, thirty handball players participating in the Greek championship volunteered to participate in this study. The subjects had a mean age of $22.9 \pm 3.4$ years, a mean weight $78.3 \pm 5.1$, and a mean height of $1.81 \pm 6.53$. None of the subjects were participating in any other physical activity except the handball training and the balance training. Also, they were free from injury in their lower limb and had no mechanical or functional instability in their knee or ankle in that period, so they were participating in regular handball training. In addition, no subject reported suffering from any systemic or vestibular-system disorders known to impair cutaneous sensation or balance. According to the team physician they did not have any biomechanical abnormality and had no other balance training activity prior to and during the entire research period.

Leg dominance was determined through the ball kick test. The players were asked to kick a ball as hard as possible. The leg used to kick the ball was recorded as the dominant leg (Hoffman and Payne, 1995; Soderman et al 2000). 


\section{Protocol}

The participants were randomly divided into two subject groups ( $\mathrm{N}=15$ each), one control group (no training intervention), and one training group (experimental group) that performed a specific balance program for 12 weeks, 3 times per week, 20 min per session. The training program included balance exercises performed on a) a mini trampoline and b) two balance boards, one with hemicylidrical base-shape restricting movement in one plane only and the other with hemispherical base-shape allowing movement in all three planes.

\section{Balance training}

Description of the balance exercise program: The exercise program was designed using principles from elite athlete training programs and those designed for rehabilitation of injured athletes with functional instability of their ankles or rupture of the anterior cruciate ligament. The main goal while designed the exercise program was to include skills that improve awareness and knee control during standing, cutting jumping and landing, which are important handball technical elements.

The subjects in the training group were asked to perform the following tasks in a random order: 1) A $2 \frac{1}{2}$ min attempt to maintain balance with one leg only on the hemicylindrical balance board performing anterior-posterior movements. 2) A $2 \frac{1}{2}$ min attempt to maintain balance with one leg only on the hemicylindrical balance board performing medial-lateral movements. 3) A $2 \frac{1}{2}$ min attempt to maintain balance with one leg only on the hemispherical balance board. 4) A $21 / 2$ min attempt to maintain balance with one leg only on the trampoline. In all tests (involving standing on the balance boards and trampoline), the subjects were asked to perform throwing exercises with a partner and complex throwing exercises to the goal.

\section{Balance assessment}

The balance ability of all subjects was assessed at baseline and after the completion of the 12-week balance-training program. The balance ability assessment was performed with the Biodex Stability System. The subjects stood with one leg only on the platform trying to maintain it as stable as possible, on the Biodex system screen. More specific the participants were asked to stood with one leg only on the system platform for $20 \mathrm{sec}$, while the platform was set to freely move with the minimal resistance available (Stability level 1) and the deviations from the horizontal were recorded on-line by the system. From the magnitude and duration of these deviations, a total instability index (TI), an Anterior -Posterior (API) and a Medial-Lateral index (MLI) was computed by the system. The subjects performed three 20 -sec practice trials and three 20 -sec test trials out of which only the best score was further processed.

Analysis

The best values were collected for each test. Means and standard deviations were calculated. Analysis of variance (ANOVA) for repeated measures was performed on recorded values to detect differences in each group for each limb. Statistical significant was accepted at $p$ $\leq 0,05$. 


\section{Results}

Analysis of the data illustrated that training group demonstrated significant improvements on Biodex stability tests, in SI $(\mathbf{p}<0.001)$, API $(\mathbf{p}<0.001)$ and MLI $(\mathbf{p}<0.001)$ for the dominant and no-dominant limb as well (Table 1 , Table 2$)$. No difference $(p>0.05)$ in balance ability was found in the control group between baseline testing and re-testing.

Table 1

Balance stability indices for the two groups, for the dominant leg through Stability System measurements

\begin{tabular}{rcc}
\hline & $\begin{array}{c}\text { Pre training } \\
\mathbf{M} \pm \text { SD }\end{array}$ & Post training \\
& $10,23 \pm 2.26$ & $\mathbf{M} \pm$ SD \\
\hline Total Index $\left({ }^{\circ}\right)$ Control & $10,54 \pm 1,41$ & $10,08 \pm 2,32$ \\
Experimental & $7,7 \pm 3,1$ & $6,47 \pm 2,34 * * *$ \\
A-P Index $\left({ }^{\circ}\right)$ Control & $7,9 \pm 3,2$ & $7,5 \pm 2,7$ \\
Experimental & $6,9 \pm 1,5$ & $4,3 \pm 1,9 * * *$ \\
M-L Index $\left(^{\circ}\right)$ Control & $6,2 \pm 1,7$ & $6,6 \pm 1,8$ \\
Experimental & & $3,7 \pm 1,6 * * *$ \\
\hline
\end{tabular}

$* * * \mathrm{p}<.001$

Table 2

Balance stability indices for the two groups, for the non-dominant leg through Stability System measurements

\begin{tabular}{rcc}
\hline & $\begin{array}{c}\text { Pre training } \\
\mathbf{M} \pm \mathbf{S D}\end{array}$ & $\begin{array}{c}\text { Post training } \\
\mathbf{M} \pm \mathbf{S D}\end{array}$ \\
\hline Total Index $\left(^{\circ}\right)$ Control & $10,67 \pm 2.41$ & $10,29 \pm 2,39$ \\
Experimental & $10,72 \pm 2,11$ & $6,12 \pm 2,73^{* * *}$ \\
A-P Index $\left(^{\circ}\right)$ Control & $7,9 \pm 3,2$ & $7,8 \pm 2,9$ \\
Experimental & $8,1 \pm 3,4$ & $4,9 \pm 2,1 * * *$ \\
M-L Index $\left(^{\circ}\right)$ Control & $7,0 \pm 1,8$ & $6,9 \pm 1,7$ \\
Experimental & $6,9 \pm 1,9$ & $3,8 \pm 1,8^{* * *}$ \\
\hline
\end{tabular}

$* * * \mathrm{p}<.001$ 


\section{Discussion}

The present study showed that the balance program improved effectively the balance ability for both legs in the experimental group. Although a lot of studies proposed that a balance exercise program improve the balance ability deficits due to injury (Caraffa et al., 1996; Chong et al., 2001; Wedderkopp et al., 1999; Gioftsidou et al., 2006), there were found no studies measuring balance parameters and their possible improvements after an application of a specific balance exercise program in healthy professional handball male players.

More specific, injury rates reductions on professional athletes after the application of balance exercise program have been recorded by many authors. Tropp et al. (1985) first showed the preventive effect of balance-board training on the incidence of ankle sprains. Caraffa et al. (1996) demonstrated in a prospective controlled study that the rate of ACL ruptures was remarkably reduced after introducing proprioceptive training on balance-boards to semiprofessional male soccer teams. Similarly, Wedderkopp and his partner (Wedderkopp et al., 1999) mentioned that the application of a balance training program on balance boards by healthy female handball players, for 10 months resulted in decrease of frequency of lower limb injuries.

As regards the assessment of balance ability after an application of a specific balance exercise program there were studies performed not on professional athletes but on healthy people. Hoffman and Payne (1995), investigated the effects of ankle disk training (BAPS) on postural sway of healthy subjects $(n=28)$ and showed significant improvements. They concluded that 10 -weeks of proprioception ankle disk training can decrease postural sway parameters significantly. Chong and his partners (2001) applied also a balance program on healthy people using balance boards ( 4 weeks, 3 times per week). The program was carried out and the participants improved their balance ability.

As concerns the content of balance training programs, which applied on healthy athletes, it has been supported that they should be adjusted to the peculiarities of each sport, simulating its activities (Tippett and Voight, 1995; Rozzi et al., 1999; Wedderkopp et al., 1999; Gioftsidou \& Malliou, 2006; Paillard et al., 2006; Ricotti et al., 2011; Ricotti, 2011). For that reason, researchers designed balance training programs that included handball skills while the player was standing on balance board (Olsen et al., 2005; Petersen et al., 2005). The design of the balance programs used in the present study is in accordance with the above theory. The specific balance exercises required the combination of balance ability and certain handball skills, like throwing exercises.

In conclusion, the application of a specific balance program for 12 weeks, 3 times per week, 20 min per session, can improve body control and increase proprioceptive ability. The exercise program designed using principles from elite athlete training programs and those designed for rehabilitation of injured athletes with functional instability. The exercise program should include skills that improve awareness and knee control during standing, cutting jumping and landing, which are important handball technical elements.

\section{References}

Bahr, R., Lian, O., \& Bahr, I. A. (1997). A twofold reduction in the incidence of acute ankle sprains in volleyball after the introduction of an injury prevention program: a prospective cohort study. Scandinavian Journal of Medicine \& Science in Sports 7(3), 172-177. 


\section{A. Gioftsidou et al.}

Caraffa, A., Cerulli, G., Projetti, M., Aisa, G., \& Rizzo, A. (1996). Prevention of anterior cruciate ligament injuries in soccer. A prospective controlled study of proprioceptive training. Knee Surgery, Sports Traumatology, Arthroscopy, 4(1), 19-21.

Chong, R. K., Ambrose, A., Carzoli, J., Hardison, L., \& Jacobson, B. (2001). Source of improvement in balance control after a training program for ankle proprioception. Perceptual and Motor Skills, 92(1), 265-72.

Gioftsidou, A., Malliou, P., Pafis, G., Beneka, A., Godolias, G., \& Maganaris C. (2006). The effects of soccer training and timing of balance training on balance ability. European Journal of Applied Physiology, 96, 659-664.

Goldie, P. A., Bach, T. M., \& Evans, O. M. (1989). Force platform measures for evaluating postural control: Reliability and validity. Archives of Physical Medicine and Rehabilitation, 70, 510-517.

Guskiewicz, K. M., \& Perrin, D. H. (1996). Research and clinical applications of assessing balance. Journal of Sport Rehabilitation, 5, 45-63.

Hanney, W. (2000). Proprioceptive training for ankle instability. Strength and Conditioning, 22(5), 63-68.

Hawkins, R. D., \& Fuller, C. W. (1999). A prospective epidemiological study of injuries in four English professional football clubs. British Journal of Sports Medicine, 33, 196-203.

Hertel, J., Braham, R. A., Hale, S. A., \& Olmsted-Kramer, L. C. (2006). Simplifying the star excursion balance test: Analyses of subjects with and without chronic ankle instability. Journal of Orthopaedic \& Sports Physical Therapy, 36, 131-137.

Hewett, T. E., Lindenfeld, T. N., Riccobene, J. V., \& Noyes, F. R. (1999). The effect of neuromuscular training on the incidence of knee injury in female athletes. A prospective study. American Journal of Sports Medicine, 27, 699-706.

Hewett, T. E., Myer, G. D., \& Ford, K. R. (2001). Prevention of anterior cruciate ligament injuries. Current Women's Health Reports, 1, 218-224.

Hoffman, M., \& Payne, G. (1995). The effects of proprioceptive ankle Disk Training on Healthy Subjects. Journal of Orthopaedic Sports Physical Therapy, 21(2), 90-93.

Hrysomallis, C. (2007). Relationship Between Balance Ability, Training and Sports Injury Risk. Sports Medicine, 37(6), 547-556.

Irrgang, J.J., Whitney, S., \& Cox, E. (1994). Balance and proprioceptive training for rehabilitation of the lower extremity. Journal of Sport Rehabilitation, 3, 68-83.

Junge, A., Rosch, D., Peterson, L., Graf-Baumann, T., \& Dvorak, J. (2002). Prevention of soccer injuries: a prospective intervention study in youth amateur players. American Journal of Sports Medicine, 30, 652-659.

Malliou, P., Gioftsidou, A., Pafis, G., Beneka, A., \& Godolias, G. (2004). Proprioceptive training (balance exercises) reduces lower extremity injuries in young soccer players. Journal of Back Musculoskeletal Rehabilitation, 17, 101-104.

McHugh, M. P., Tyler, T., Mirabella, M., Mullaney, M., \& Nicholas, S. (2007). The effectiveness of a balance training intervention in reducing the incidence of noncontact ankle sprains in high school football players. American Journal of Sports Medicine, 35(8), 1289-1294.

Meeuwisse, W. H., Sellmer, R., \& Hagel, B. E. (2003). Rates and risks of injury during intercollegiate basketball. American Journal of Sports Medicine, 31, 379-385. 
The effects of balance traininq in handball players

Olmsted, L. C., Carcia, C. R., Hertel, J., \& Shultz, S. J. (2002). Efficacy of the star excursion balance tests in detecting reach deficits in subjects with chronic ankle instability. Journal of Athletic Training, 37, 501-506.

Olsen, O., Myklebust, G., Engebretsen, L., Holme, I., \& Bahr, R. (2005). Exercises to prevent lower limb injuries in youth sports: cluster randomised controlled trial. British Medical Journal, 330, 449-452.

Paillard, T., Noe, F., Riviere, T., Marion, V., Montoya, R., \& Dupui, P. (2006). Postural performance and strategy in the unipedal stance of soccer players at different levels of competition. Journal of Athletic Training, 41(2), 172-176.

Petersen, W., Zantop, T., Steensen, M., Hypa, A., Wessolowski, T., \& Hassenpflug, J. (2002). Prevention of lower extremity injuries in handball: initial results of the handball injuries prevention programme. Sportverletz Sportschaden, 16, 122-126.

Petersen, W., Braun, C., Bock, W., Schmidt, K., Weimann, A., Drescher, W., et al. (2005). A controlled prospective case control study of a prevention training program in female team handball players: the German experience. Archives of Orthopaedic and Trauma Surgery, 125(9), 614-621.

Ricotti, L. (2011). Static and dynamic balance in young athletes. Journal of Human Sport \& Exercise, 6(4), 616-628.

Ross, S. E., \& Guskiewicz, K. M. (2004). Examination of static and dynamic postural stability in individuals with functionally stable and unstable ankles. Clinical Journal of Sport Medicine, 14, 332-338.

Rozzi, S. L., Lephart, S. M., Sterner, R., \& Kuligowski, L. (1999). Balance training for persons with functionally unstable ankles. Journal of Orthopaedic Sports Physical Therapy, 29(8), 478-486.

Sammarco, G. J. (1995). Rehabilitation of the foot and ankle. St. Louis, Missouri: Mosby-Year Book.

Soderman, K., Werner, S., Pietila, T., Engstrom, B., \& Alfredson. H. (2000). Balance board training: prevention of traumatic injuries of the lower extremites in female soccer players? A prospective randomized intervention study. Knee Surgery and Sports Traumatology Arthroscopy, 8, 356-363.

Tippett, S., \& Voight, M. (1995). Functional Progressions for Sport Rehabilitation. Human Kinetics.

Tropp, H., Askling, C., \& Gillquist, J. (1985). Prevention of ankle sprains. American Journal of Sports Medicine, 13, 259-262.

Wedderkopp, N., Kalthoft, M., Lundgaard, B., Rosendahl, M., \& Froberg, K. (1997). Injuries in young female players in European team handball. A prospective intervention study. Scandinavian Journal of Medicine and Science in Sports, 7, 342-347.

Wedderkopp, N., Kaltoft, M., Lundgaard, B., Rosendahl, M., \& Froberg. K. (1999). Prevention of injuries in young female players in European team handball. A prospective intervention study. Scandinavian Journal of Medicine and Science in Sports, 9, 41-47.

Wedderkopp, N., Kaltoft, M., Holm, R., \& Froberg, K. (2003). Comparison of two intervention programmes in young female players in European handball - with and without ankle disc. Scandinavian Journal of Medicine and Science in Sports, 13, 371-375.

Zachazewski, J., Magee, D., \& Quillen, W. (1996). Athletic injuries and rehabilitation. W.B. Saunders Company, pp. 236-261. 


\section{A. Gioftsidou et al.}

Zech, A., Hubscher, M., Vogt, L., Banzer, W., Hansel, F., \& Pfeifer, K. (2009). Neuromuscular training for rehabilitation of sports injuries. A systematic review. Medicine \& Science in Sports \& Exercise, 41, 1831-1841. 